\title{
Patient-Reported Outcomes of Bleomycin Sclerotherapy for Low- Flow Vascular Malformations and Predictors of Improvement
}

\author{
S. E. R. Horbach ${ }^{1}$ J. S. van de Ven ${ }^{1}$ P. T. Nieuwkerk ${ }^{2} \cdot$ Ph. I. Spuls ${ }^{3}$. \\ C. M. A. M. van der Horst ${ }^{1}$ - J. A. Reekers ${ }^{4}$
}

Received: 11 January 2018/Accepted: 21 May 2018/Published online: 8 June 2018

(C) The Author(s) 2018

\begin{abstract}
Purpose There is paucity of data on patient-perceived outcomes of bleomycin sclerotherapy for low-flow vascular malformations. In this study, the long-term outcomes of bleomycin sclerotherapy were investigated in terms of quality of life $(\mathrm{QoL})$ and patient-perceived changes in health.

Materials and Methods A cohort of Dutch patients with vascular malformations treated with bleomycin sclerotherapy (June 2010-November 2015) completed a questionnaire evaluating disease symptoms, QoL (Short Form 36), patient-perceived change in health status (Global Rating of Change scales) and treatment satisfaction. QoL was assessed for the patient's status before and after treatment and was analyzed relative to an age and sexmatched Dutch reference population. Predictive factors associated with QoL and patient-perceived improvement in overall health status were assessed using multivariable linear and logistic regression analyses, respectively.
\end{abstract}

C. M. A. M. van der Horst and J. A. Reekers have contributed equally to the manuscript.

S. E. R. Horbach

s.e.horbach@amc.uva.nl

1 Department of Plastic, Reconstructive and Hand Surgery, Academic Medical Center (AMC), P.O. Box 22660, 1100 DD Amsterdam, The Netherlands

2 Department of Medical Psychology, Academic Medical Center (AMC), Amsterdam, The Netherlands

3 Department of Dermatology, Academic Medical Center (AMC), Amsterdam, The Netherlands

4 Department of Radiology, Division of Interventional Radiology, Academic Medical Center (AMC), Amsterdam, The Netherlands
Results Seventy-seven patients, with a median follow-up of 22 months, were enrolled. About half of the respondents $(49.3 \%)$ indicated that they perceived (any form of) improvement in their overall health status. Most often improved were the specific health aspects 'pain' (54.5\%) and 'overall severity of symptoms' $(57.1 \%)$. No factors were significantly predictive for patient-perceived improvement in health with respect to the vascular malformation. Impairment in work- or study-related activities prior to sclerotherapy was found to negatively impact physical QoL at follow-up $(p=0.03)$.

Conclusion Approximately half of patients with low-flow vascular malformations indicate an improvement in overall health status following bleomycin sclerotherapy, particularly concerning pain and severity of symptoms. However, most patients only perceived little to moderate improvement to their health and desire further treatment.

Keywords Bleomycin - Sclerotherapy · Vascular malformations · Venous malformations $\cdot$ Lymphatic malformations

\section{Introduction}

Low-flow vascular malformations, defined as lymphatic malformations (LMs), venous malformations (VMs) or combined lymphatic-venous malformations (LVMs) [1, 2], can cause a great variety of complaints ranging from pain to dissatisfaction with appearance, which can dramatically affect the patient's quality of life (QoL) [3, 4]. 
With sclerotherapy, the affected vessels can be targeted using a sclerosing agent that causes endothelial dysfunction or destruction and an immunologic response followed by thrombotic occlusion and regression of the vascular malformation vessels [5-7]. Sclerotherapy can be used as a stand-alone therapy or can be performed in combination with other procedures such as surgery or laser therapy [8]. Although many sclerosing agents, such as ethanol, etoxysclerol, polidocanol and OK-432, can be used for this goal [8-13], there is no consensus about which sclerosing agent is superior since well-designed randomized comparative trials have not yet been performed [8, 14]. Bleomycin is a sclerosing agent used for vascular malformations $[12,15]$, that was originally discovered for its cytotoxic and antibiotic properties [16-18]. As clinicians noticed that bleomycin also has a potent sclerosing effect, and may lead to less severe local adverse events (e.g., swelling, nerve injury) than other sclerosing agents [19-21], it is now one of the most frequently used sclerosing agents for vascular malformations [8]. Previously published observational studies show that bleomycin can reduce the size of both LMs and VMs [12, 15]. However, this is usually measured with non-radiologic assessments of change in size or appearance that are subject to the perception of the physician [12]. Although patients regularly undergo treatment to improve subjective complaints such as their symptoms, cosmetic appearance or their healthrelated QoL, these outcomes are rarely measured from the perspective of the patient. The objective of this study is therefore to explore the long-term treatment outcomes of bleomycin sclerotherapy from the perspective of the patient by using an existing patient-reported outcome measures (PROM) to measure QoL and patient-perceived changes in health after treatment. Furthermore, we aimed to identify variables that are associated with patient-perceived improvement and health-related QoL.

\section{Materials and Methods}

\section{Study Design}

A retrospective follow-up study was performed to assess patients' perceptions of changes in QoL and various health aspects following bleomycin sclerotherapy in an academic vascular anomalies center.

\section{Treatment Procedure}

In our center, bleomycin is the sclerosing agent of choice for VMs, LMs and LVMs. Prior to treatment, all vascular malformations were assessed for flow characteristics, location and extent of the lesion using non-contrast- enhanced T1- and T2-weighted magnetic resonance imaging (MRI) and/or ultrasonography. Sclerotherapy procedures were performed under deep sedation by an experienced interventional radiologist (J.R. or R.v.d.B.) in the interventional radiologic suite. The vascular malformation is accessed percutaneously using a 22 -gauge winged needle under ultrasonographic guidance. Before injecting bleomycin, local phlebography with a non-ionic contrast medium (iodixanol, $320 \mathrm{mg}$ iodine/ml; Visipaque, GE Healthcare, A.S., Oslo, Norway) is performed, following the digital subtraction angiography (DSA) technique, to exclude any direct communication to the systemic circulation and to image the local anatomy of the vascular malformation. Bleomycin (Bleomedac, 15,000 IU/15 mg) is then selectively injected in the venous or lymphatic dilatations only under direct sonographic guidance. After the injections, a local pressure bandage is applied for $6 \mathrm{~h}$. Six weeks after each treatment session, the interventional radiologist assesses clinical response by evaluating symptom relief and visible improvement of the lesion's size or appearance upon physical examination. If needed, one or more subsequent treatment sessions may be scheduled. In general, the treatment procedure is terminated when there is no (additional) beneficial effect observed after two consecutive treatment sessions or when the patient is satisfied with the result.

\section{Study Procedure}

\section{Patient Selection and Eligibility}

Adult patients with low-flow vascular malformations (VMs, LMs or LVMs) who underwent bleomycin sclerotherapy as a stand-alone treatment between June 2010 and November 2015 were identified through the prescription database of the hospital pharmacy. Patients treated with bleomycin for diagnoses other than low-flow vascular malformations were excluded. Eligible patients were mailed or e-mailed with an invitation to complete the questionnaire in October 2016, either online or in hard copy. Reminders were sent after 3 and 6 weeks.

\section{Questionnaire}

Currently, there are no validated patient-reported outcome measures available for patients with vascular malformations. In order to explore the outcome of bleomycin sclerotherapy from the perspective of the patient, the generic QoL measure Short Form 36-item Health Survey (SF-36), global rating of change scales and a treatment satisfaction scale were incorporated in an online questionnaire (SurveyMonkey Inc, San Mateo, California, USA). 
The $S F-36$ is a generic multidimensional instrument that is composed of 36 items sorted into eight multi-item scales representing: (1) physical functioning $(\mathrm{PF})$; (2) role-functioning physical (RP, assesses the extent to which physical health interferes with work or everyday responsibilities); (3) bodily pain (BP); (4) general health perceptions (GH); (5) vitality (VT); (6) social functioning (SF); (7) rolefunctioning emotional (RE, extent to which, emotional problems cause limitations in work or daily activities); (8) mental health $(\mathrm{MH})$ [22]. With these domains, summary scores can be calculated for the physical component summary (PCS) score and the mental component summary (MCS) score. In this study, the SF-36 was used to assess patients' follow-up QoL at the time of completing the survey, and in the absence of baseline data, the SF-36 was also utilized for a retrospective baseline measurement. For this purpose, questions from the SF-36 were rephrased to refer to the period before bleomycin sclerotherapy.

Global Rating of Change (GRC) scales were applied to gain insight into the magnitude of patient's perceived changes that occurred following bleomycin sclerotherapy. Patients rated their perceived change on a 7-point Likert scale ranging from -3 (worst possible deterioration) to +3 (best possible improvement). Domains that were rated were overall health status with respect to the vascular malformation (patient's impression of 'overall change' in health), pain, physical well-being, mobility of affected body part, patient-perceived appearance, overall severity of symptoms, work- or study-related activities, emotional wellbeing and social activities. Although GRC scales are not specifically validated for vascular malformations, they have been used in diverse patient populations and, overall, clinimetric properties such as face validity and responsiveness have shown to be acceptable [23-25].

Satisfaction with the treatment procedure and treatment outcome was rated by the patient on a numeric rating scale from 0 (extremely dissatisfied) to 10 (extremely satisfied).

\section{Data Collection from Electronic Patient File}

The following patient and treatment characteristics were extracted from the electronic patient file: demographics, type of vascular malformations, size categorized based on the largest diameter of the lesion measured on MRI prior to treatment, symptoms prior to treatment, location, lesion depth, prior treatments, sclerotherapy doses and number treatment sessions, complications and follow-up time.

\section{Data Analyses}

Descriptive data were presented for the patient and treatment characteristics, SF-36 scores, GRC scales and satisfaction scores. Mean scores and standard deviations (SD) were used for SF-36 scores and normally distributed data, and median and interquartile ranges were presented for nonparametric data. A paired $t$ test was performed to explore the statistical difference between retrospective baseline SF-36 scores and follow-up SF-36 scores.

The 8 dimensions of the SF-36 score were converted to standard scores (Z-scores) on the basis of the scores of ageand sex-matched norms of a representative Dutch population sample [26]. Z-scores were calculated by dividing the difference between the patients' SF-36 score and the mean score of the age- and sex- matched reference population by the SDs of the reference population. A Z-score indicates how many SDs the observed SF-36 score falls below or above the score of the reference population. Statistical differences between the mean standard scores of the vascular malformation group and the reference population were assessed by means of a one-sample t test. KruskalWallis tests and post hoc Mann-Whitney $U$ tests with Bonferroni correction were computed to explore statistical differences between subgroups of vascular malformation types, sizes and locations.

Bivariate and stepwise multivariable linear regression analyses, adjusted for age and sex, were performed to identify variables predictive for patients' follow-up SF 36 scores (MCS and PCS), with and without adjustment for the retrospective baseline scores. The analysis without adjustment for the retrospective baseline measurement would yield predictors of a better QoL in general. The analysis with adjustment for the retrospective baseline measurement would explore the predictors of improvement in QoL.

A logistic regression analysis was performed to assess the influence of pre-defined possible predictors (age during treatment, sex, vascular malformation size, vascular malformation type, location of the vascular malformation and symptoms prior to treatment) on the patient's global rating of improvement. These variables were entered in the multivariable regression analysis when they yielded $p$ values $<0.20$ in bivariate analyses. Assumption checks regarding multicollinearity, outliers, normality, linearity and homoscedasticity were performed for the multivariable linear regression models. A two-sided $p$ value of 0.05 or less was considered statistically significant, and a $95 \%$ confidence interval (CI) was used. Data analyses were performed using Statistical Package for the Social Sciences (SPSS version 24.0; IBM Corp, Armonk, NY, USA). 


\section{Results}

\section{Patient and Treatment Characteristics}

A total of 134 adult patients who were treated with bleomycin injections for a low-flow vascular malformation were identified from the hospital prescription database and were invited to participate in the study. Seventy-seven of these patients $(57.5 \%)$ completed the questionnaire
(Fig. 1). Patient demographics are shown in Table 1. The median follow-up period from the last treatment session with bleomycin sclerotherapy until completing the questionnaire was 22 months. The majority of patients had VM $(81.8 \%)$. The most common symptoms reported prior to treatment were pain $(74.0 \%)$, impaired mobility of the affected body part (49.4\%) and dissatisfaction with appearance $(37.7 \%)$. Five patients underwent treatment procedures other than bleomycin sclerotherapy in the

Patients with a prescription for bleomycin for intralesional use identified through the hospital pharmacy $(n=210)$

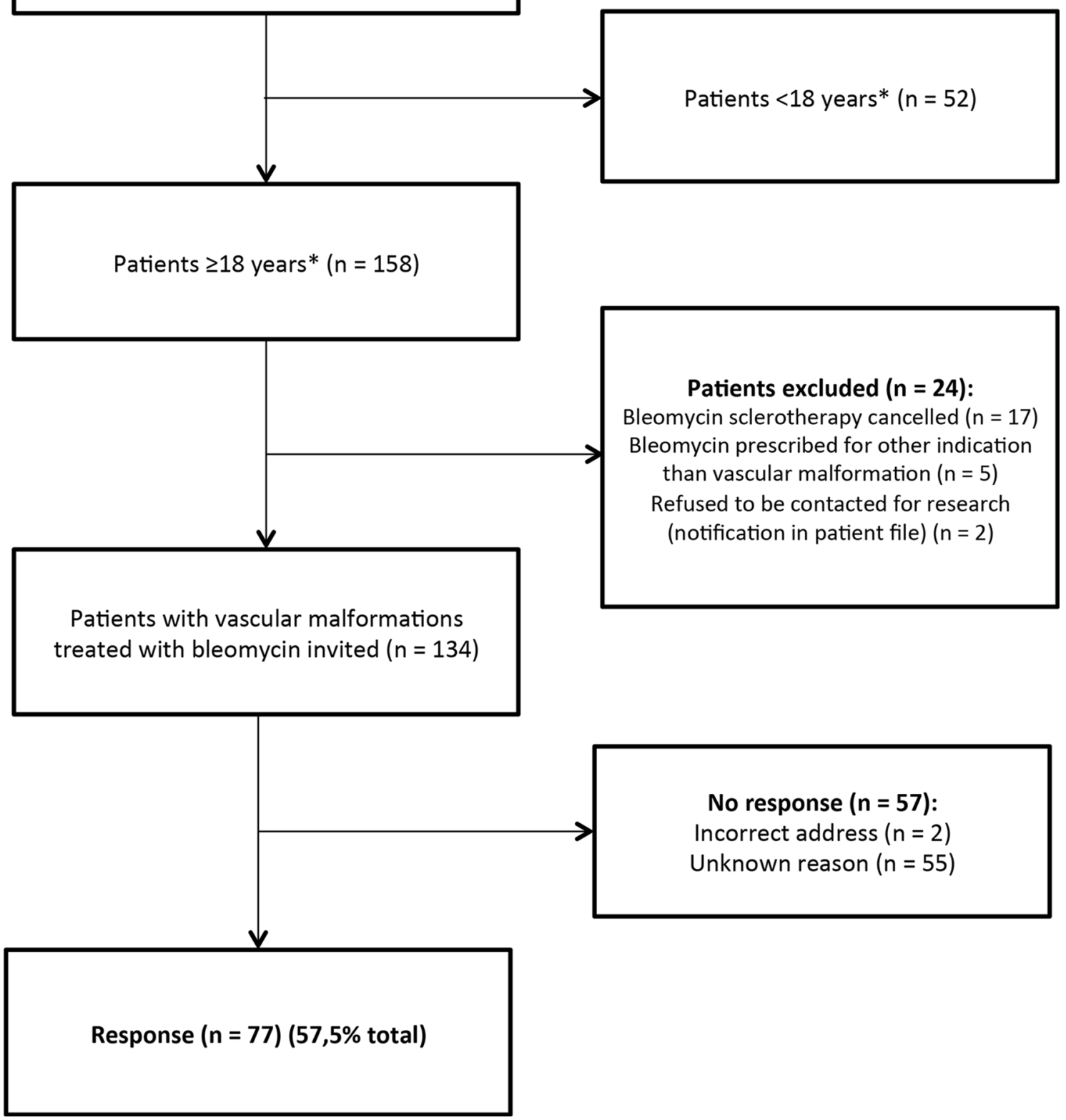

Fig. 1 Flowchart of patient enrollment 
Table 1 Patient characteristics

\begin{tabular}{lll}
\hline Patients $n=77$ & Median & $\begin{array}{l}\text { IQR (25th-75th } \\
\text { percentile) }\end{array}$ \\
\hline Age (years) & 35 & $26(24-49.5)$ \\
$\begin{array}{l}\text { Follow-up time since last bleomycin } \\
\text { injection (months) }\end{array}$ & 22 & $19(14-32)$ \\
$\begin{array}{l}\text { Number of bleomycin sclerotherapy } \\
\text { sessions }\end{array}$ & 2 & $1(1-2)$ \\
\hline & Number Percent \\
& & $(\%)$ \\
\hline
\end{tabular}

\section{Gender}

Female

50

Educational level

No education

High school

Intermediate professional education

Higher professional education (Bachelor's degree)

Academic education (Master's degree)

Vascular malformation type

VM

LM

LVM

$\mathrm{VM}$ combined with port-wine stain

Location of vascular malformation

Head and neck

Trunk

Upper extremities

Lower extremities

Lesion size

$0-5 \mathrm{~cm}$

$5-10 \mathrm{~cm}$

$>10 \mathrm{~cm}$

Not reported

Lesion depth

Skin

Subcutaneous

Muscle

Bone

Not reported

Diagnostic imaging

Ultrasound

MRI

CT

X-ray

Diagnostic histologic biopsy

Previous therapies

Sclerotherapy (non-bleomycin)

Surgery

\section{9}

1.3

11.7

36.4

15.6

81.8

10.4

6.5
Table 1 continued

\begin{tabular}{|c|c|c|}
\hline & Number & $\begin{array}{l}\text { Percent } \\
(\%)\end{array}$ \\
\hline Laser therapy & 7 & 9.1 \\
\hline Compression therapy & 22 & 28.6 \\
\hline Cryotherapy & 1 & 1.3 \\
\hline Radiotherapy & 1 & 1.3 \\
\hline None & 19 & 24.7 \\
\hline \multicolumn{3}{|l|}{ Symptoms prior to bleomycin sclerotherapy* } \\
\hline Pain & 57 & 74.0 \\
\hline Itch & 10 & 13.0 \\
\hline Recurrent bleedings & 8 & 10.4 \\
\hline Recurrent infections & 5 & 6.5 \\
\hline $\begin{array}{l}\text { Recurrent phleboliths/localized intravascular } \\
\text { coagulation }\end{array}$ & 11 & 14.3 \\
\hline Impaired mobility of affected body part & 38 & 49.4 \\
\hline Location-specific symptoms** & 2 & 2.6 \\
\hline Fatigue & 5 & 6.5 \\
\hline Impaired physical condition & 20 & 26.0 \\
\hline Impaired in work- or study-related activities & 20 & 26.0 \\
\hline Impaired in social activities & 15 & 19.5 \\
\hline Dissatisfaction with appearance & 29 & 37.7 \\
\hline Emotional/psychological issues & 8 & 10.4 \\
\hline No symptoms & 1 & 1.3 \\
\hline
\end{tabular}

*Question not answered by 2 patients. **Symptoms associated with the location of the vascular malformation (e.g., visual disturbance, swallowing difficulties)

follow-up period: surgery $(n=2)$, laser therapy $(n=1)$ or sclerotherapy with a different sclerosing agent $(n=2)$.

A total of 151 sclerotherapy sessions were performed in the included 77 patients. The number of sclerotherapy sessions ranged between 1 and 6 , with a median of 2 treatment sessions. A concentration of $1 \mathrm{mg}(\sim 1000 \mathrm{IU})$ per $\mathrm{ml}$ bleomycin was generally utilized, for smaller vascular malformations $(<5 \mathrm{~cm})$ a concentration of $3 \mathrm{mg}$ $(\sim 3000 \mathrm{IU})$ per $\mathrm{ml}$ was used $(n=31,23.5 \%)$.The total dose per session ranged from 1 to $18 \mathrm{mg}$, with a mean dose of $10.18 \mathrm{mg}$ (SD 5.02). The cumulative doses ranged from 2 to a maximum of $90 \mathrm{mg}$ with a mean of $18.34 \mathrm{mg}$ (SD $16.06 \mathrm{mg}$ ).

\section{Patient-Reported Health-Related QoL}

The sum scores of the SF-36 scales and subscales are shown in Table 2. Patients' follow-up SF-36 scores were significantly higher than their retrospective baseline scores on the following scales: the physical composite scale (PCS) $(p<0.01)$, and the subscales physical functioning (PF) $(p=0.01)$, role physical (RP) $(p=0.03)$, BP $(p<0.01)$, social functioning (SF) $(p<0.01)$ and mental health $(\mathrm{MF})$ 
Table 2 Short-Form-36 (SF-36) scores

\begin{tabular}{|c|c|c|c|c|c|}
\hline & \multirow{2}{*}{$\begin{array}{l}\text { Retrospective } \\
\text { baseline SF-36 } \\
\text { Mean } \pm \text { SD }\end{array}$} & \multirow{2}{*}{$\begin{array}{l}\text { Follow-up } \\
\text { SF-36* } \\
\text { Mean } \pm \text { SD }\end{array}$} & \multicolumn{3}{|l|}{ Paired $t$ test } \\
\hline & & & Mean of the difference \pm SD & $95 \%$ CI of difference & $p$ value \\
\hline PCS & $46.34 \pm 10.11$ & $49.19 \pm 9.43$ & $2.85 \pm 6.58$ & $1.32 ; 4.39$ & 0.00 \\
\hline MCS & $50.77 \pm 8.56$ & $51.26 \pm 7.60$ & $0.49 \pm 7.56$ & $-1.27 ; 2.25$ & 0.58 \\
\hline Physical functioning & $81.28 \pm 19.18$ & $84.91 \pm 17.42$ & $3.63 \pm 11.71$ & $0.95 ; 6.30$ & 0.01 \\
\hline Role physical & $71.49 \pm 35.85$ & $78.95 \pm 34.65$ & $7.46 \pm 29.58$ & $0.70 ; 14.22$ & 0.03 \\
\hline Bodily pain & $56.46 \pm 29.44$ & $68.33 \pm 28.68$ & $11.87 \pm 20.01$ & $7.30 ; 16.44$ & $<0.001$ \\
\hline Social functioning & $75.49 \pm 26.78$ & $84.25 \pm 20.01$ & $8.77 \pm 22.59$ & $3.64 ; 13.89$ & 0.001 \\
\hline Mental health & $76.96 \pm 13.17$ & $79.56 \pm 13.17$ & $2.60 \pm 10.20$ & $0.25 ; 4.94$ & 0.03 \\
\hline Role emotional & $84.64 \pm 32.86$ & $83.77 \pm 32.88$ & $-0.88 \pm 30.78$ & $-7.91 ; 6.16$ & 0.80 \\
\hline Vitality & $66.73 \pm 16.11$ & $66.87 \pm 18.56$ & $0.13 \pm 11.59$ & $-2.53 ; 2.80$ & 0.92 \\
\hline General health perceptions & $72.36 \pm 20.21$ & $73.48 \pm 20.29$ & $1.12 \pm 11.89$ & $-1.61 ; 3.85$ & 0.41 \\
\hline
\end{tabular}

Bold values indicate statistical significance $(p<0.05)$

PCS physical component summary score, MCS mental component summary score

*At the time of completing the questionnaire: median follow-up of 22 months after bleomycin sclerotherapy

$(p=0.03)$. The mental composite scale (MCS) was not statistically improved. There were no statistical differences in QoL scores between patients with LMs, VMs and LVMs (PCS $p=0.34$, MCS $p=0.84$ ) and between patients with different malformation sizes (PCS $p=0.25$; MCS $p=0.23$ ). At follow-up, the PCS scores of patients with vascular malformations in the upper and lower extremities were significantly lower, compared to vascular malformation in the head and neck region $(p<0.05$ and $p<0.005$, respectively). The MCS scores did not statistically differ between the location subgroups ( $p=0.18$ ).

When these results are analyzed relative to a general Dutch reference population (shown in Fig. 2), the patients' retrospective baseline scores on physical functioning (PF), role physical (RP), bodily pain (BP) and social functioning (SF) were significantly lower than the age- and sex-matched reference population. At follow-up, only the subscales physical functioning (PF) and bodily pain (BP) remained significantly lower.

\section{Patient-Reported Global Ratings of Change (GRC)}

As shown in Table 3, 49.3\% percent of patients indicated that there had been some level of improvement in their overall health status with respect to the vascular malformation following bleomycin sclerotherapy, whereas the remaining patients indicated that their overall health status was unchanged $(39.0 \%)$ or even deteriorated $(11.7 \%)$. These ratings did not significantly differ between LMs, VMs, and LVMs $(p=0.71)$, different size categories $(p=0.79)$ or locations $(p=0.97)$. A decrease in pain was noted by $54.5 \%$ of the total number of participating patients, and an improvement in overall severity of symptoms was reported by $57.1 \%$ of patients. Both mobility of the affected body part and cosmetic appearance were considered improved by $42.9 \%$ of patients. Physical well-being $(23.4 \%)$, work- or study-related activities (31.2\%), emotional well-being $(22.1 \%)$ and social activities $(27.1 \%)$ improved in a smaller subset of patients. In general, patients rated their improvement on all GRC scales predominantly as 'a little better' and only sporadically as 'very much better,' indicating that the majority of patients only perceived slight changes to these different aspects of their health.

\section{Treatment Satisfaction}

Patients rated their satisfaction with treatment outcome with a median of 6 (IQR 3.25-8.00) and satisfaction with the treatment procedure received a median rating of 7 (IQR $5.00-8.00$ ). A majority of $63.6 \%$ of patients expressed a desire for further treatment, mostly because the beneficial effects of bleomycin sclerotherapy did not last or because of clinically significant residual disease.

\section{Predictive Variables for QoL and Patient-Perceived Improvement}

Location in the lower extremities and complaints of fatigue, dissatisfaction with appearance and impairment in work- or study-related activities prior to treatment were significant predictors of having lower follow-up PCS scores, indicating a worse physical QoL. When adjusted for retrospective baseline PCS scores, only the latter factor 


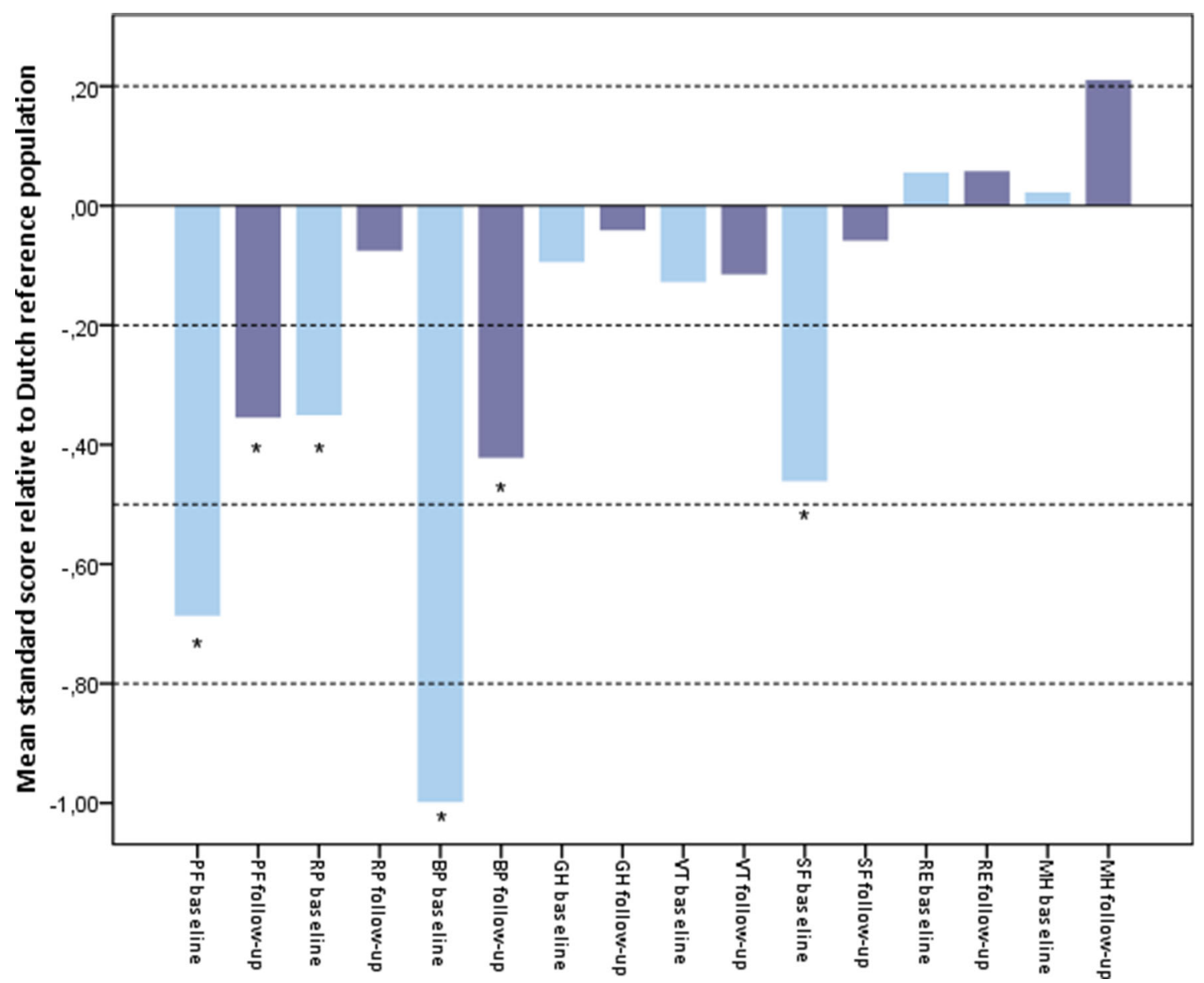

Fig. 2 Bar chart of Z-scores of SF-36 domains corrected for age and sex, compared to Dutch reference population mean. The Z-scores or 'standard mean scores' indicate how many standard deviations the patient's score is from the mean of the Dutch reference population. A Z-score of zero (horizontal line) therefore indicates a score conform the reference population. A negative score indicates a lower and a positive score a higher score than the reference population mean.* indicates a significant difference compared with the Dutch reference population. The dotted horizontal lines at standard mean scores of 0.2 ,

remained significantly predictive of a lower follow-up PCS score. There were no factors that contributed significantly to the regression models for the MCS follow-up scores (mental QoL) and overall improvement in health status (Table 4).

\section{Discussion}

About half of the patients indicated that they noticed any form of improvement in their health status with respect to the vascular malformation after a median follow-up period of 22 months. Particularly pain and overall severity of symptoms were considered improved. However, our data suggest that subtle health changes are generally more likely
0.5 and 0.8 represent small, moderate and large deviations from the reference population, respectively. Baseline = retrospectively assessed baseline SF-36 score for situation prior to bleomycin sclerotherapy. Follow-up = SF-36 scores after bleomycin sclerotherapy, at the time of completing the questionnaire (median follow-up 22 months). $\mathrm{PF}=$ physical functioning, $\mathrm{RP}=$ role physical, $\mathrm{BP}=$ bodily pain, $\mathrm{GH}=$ general health, $\mathrm{VT}=$ vitality, $\mathrm{SF}=$ social functioning, $\mathrm{RE}=$ role emotional, $\mathrm{MH}=$ mental health

to occur than drastic improvements. The majority of patients indicate that they desire further treatment.

A possible explanation for the moderate to low patient satisfaction scores could be that the patients' expectations exceeded the outcomes that could realistically be achieved. In general, long-term complete remission is rarely observed in the management of vascular malformations. Therefore, vascular malformations may be considered as a chronic disease, and patients may require multiple therapeutic interventions during their life course to minimize symptoms and to improve cosmetic appearance. The expectations of patients should be managed accordingly with clear patient-physician communication about the risks, benefits and expectations of treatment. 
Table 3 Patient-reported scores on the global rating of change (GRC) scales

\begin{tabular}{|c|c|c|c|c|c|c|c|c|c|c|c|c|c|c|c|c|c|c|}
\hline & \multicolumn{2}{|c|}{$\begin{array}{l}\text { Overall } \\
\text { health status } \\
\text { with respect } \\
\text { to vascular } \\
\text { malformation }\end{array}$} & \multicolumn{2}{|c|}{ Pain } & \multicolumn{2}{|c|}{$\begin{array}{l}\text { Physical } \\
\text { well- } \\
\text { being }\end{array}$} & \multicolumn{2}{|c|}{$\begin{array}{l}\text { Mobility } \\
\text { of the } \\
\text { affected } \\
\text { body part }\end{array}$} & \multicolumn{2}{|c|}{ Appearance/cosmetics } & \multicolumn{2}{|c|}{$\begin{array}{l}\text { Severity } \\
\text { of } \\
\text { symptoms }\end{array}$} & \multicolumn{2}{|c|}{$\begin{array}{l}\text { Work- or } \\
\text { study- } \\
\text { related } \\
\text { activities }\end{array}$} & \multicolumn{2}{|c|}{$\begin{array}{l}\text { Emotional } \\
\text { well-being }\end{array}$} & \multicolumn{2}{|c|}{$\begin{array}{l}\text { Social } \\
\text { activities }\end{array}$} \\
\hline & $n$ & $\%$ & $n$ & $\%$ & $n$ & $\%$ & $n$ & $\%$ & $n$ & $\%$ & $n$ & $\%$ & $n$ & $\%$ & $n$ & $\%$ & $n$ & $\%$ \\
\hline Improved & 38 & 49.3 & 42 & 54.5 & 18 & 23.4 & 33 & 42.9 & 33 & 42.9 & 44 & 57.1 & 24 & 31.2 & 17 & 22.1 & 21 & 27.3 \\
\hline $\begin{array}{l}\text { Somewhat } \\
\text { better }\end{array}$ & 8 & 10.4 & 16 & 20.8 & 8 & 10.4 & 16 & 20.8 & 18 & 23.4 & 18 & 23.4 & 9 & 11.7 & 9 & 11.7 & 7 & 9.1 \\
\hline Better & 15 & 19.5 & 17 & 22.1 & 7 & 9.1 & 12 & 15.6 & 10 & 13.0 & 17 & 22.1 & 11 & 14.3 & 5 & 6.5 & 10 & 13.0 \\
\hline $\begin{array}{l}\text { Very much } \\
\text { better }\end{array}$ & 15 & 19.5 & 9 & 11.7 & 3 & 3.9 & 5 & 6.5 & 5 & 6.5 & 9 & 11.7 & 4 & 5.2 & 3 & 3.9 & 4 & 5.2 \\
\hline No change & 30 & 39.0 & 23 & 29.9 & 49 & 63.6 & 31 & 40.3 & 34 & 44.2 & 21 & 27.3 & 46 & 59.7 & 56 & 72.7 & 53 & 68.8 \\
\hline Deteriorated & 9 & 11.7 & 12 & 15.6 & 10 & 13.0 & 13 & 16.9 & 10 & 13.0 & 12 & 15.6 & 7 & 9.1 & 4 & 5.2 & 3 & 3.9 \\
\hline $\begin{array}{l}\text { Somewhat } \\
\text { worse }\end{array}$ & 4 & 5.2 & 4 & 5.2 & 6 & 7.8 & 9 & 11.7 & 9 & 11.7 & 8 & 10.4 & 5 & 6.5 & 3 & 3.9 & 2 & 2.6 \\
\hline Worse & 3 & 3.9 & 7 & 9.1 & 4 & 5.2 & 4 & 5.2 & 0 & 0.0 & 3 & 3.9 & 2 & 2.6 & 1 & 1.3 & 1 & 1.3 \\
\hline $\begin{array}{l}\text { Very much } \\
\text { worse }\end{array}$ & 2 & 2.6 & 1 & 1.3 & 0 & 0.0 & 0 & 0.0 & 1 & 1.3 & 1 & 1.3 & 0 & 0.0 & 0 & 0.0 & 0 & 0.0 \\
\hline
\end{tabular}

In retrospect, patients seemed to perceive a better health-related QoL after bleomycin sclerotherapy when comparing to their recalled baseline situation, particularly on the physical subscales such as bodily pain and physical functioning, which would imply that especially psychical QoL may be improved with bleomycin sclerotherapy. Impairment in work- or study-related activities prior to treatment was the only factor that negatively influences physical QoL at follow-up. It is likely that patients with extensive disease, who are already severely impaired in daily life, cannot expect much improvement in this area following bleomycin sclerotherapy.

This study focuses on patient-reported outcomes, an undervalued type of outcome measurement in this patient category, despite the fact that the reasons for initiating therapy are very often patient subjective. However, assessing patients' perceptions of health and QoL is difficult. This study was limited because of its retrospective study design, which made it impossible to perform a true baseline measurement. Consequently, the retrospective baseline measurement that was performed could have been affected by memory effects or 'recall bias' [27]. Another limitation was that we were restricted to a relatively small sample size for our regression analyses, as vascular malformations are uncommon. Nevertheless, we believe that the results of these exploratory analyses are important for guidance in clinical practice, as information about patientperceived outcomes and predictive factors for improvement was not yet available and could assist physicians in therapeutic decision-making.
Systematic reviews that were largely based on physician-reported outcomes, report a favorable overall response following bleomycin sclerotherapy in 68-100\% of treated patients with head and neck vascular malformations [8] and a good to excellent outcome in $87 \%$ of VMs and $84 \%$ of LMs in any locations of the body [12]. It seems that the patient-perceived improvement in this study is far more modest than the physician-perceived outcomes of improvement that have been published so far. These findings highlight the importance of including standardized patient-reported outcome measures in future studies.

This patient cohort had lower scores on various domains the SF-36 QoL questionnaire compared to the Dutch reference population. These results were largely in line with the findings of other authors [3, 28]. A study of Ono et al. in patients with VM treated with sclerotherapy (unspecified agent) demonstrates a significant improvement in the SF36 domains role physical, bodily pain and social functioning, which is consistent with our findings [29]. Although this would suggest that change in QoL after treatment in this patient population can be captured by the SF-36, it is important to further investigate the measurement properties of the SF-36 in this patient population with prospectively collected data. For example, it needs to be determined if the SF-36 can adequately measure a change in health status (responsiveness) and which changes in scores are clinically meaningful for patients (interpretability). Furthermore, development and validation of disease-specific PROMs may further benefit outcome measurement in this field. 
Table 4 Multivariable logistic regression model of overall improvement and linear regression models for SF-36 PCS and MCS follow-up scores

\begin{tabular}{|c|c|c|c|c|c|c|c|c|c|c|c|}
\hline & \multicolumn{3}{|c|}{$\begin{array}{l}\text { Multivariable logistic } \\
\text { regression }\end{array}$} & \multicolumn{8}{|c|}{ Multivariable linear regression } \\
\hline & & & & SF-36 P & & & & SF-36 M & ICS & & \\
\hline & \multicolumn{3}{|c|}{$\begin{array}{l}\text { Overall patient-reported } \\
\text { improvement }\end{array}$} & \multicolumn{2}{|c|}{$\begin{array}{l}\text { Not adjusted for } \\
\text { baseline PCS }\end{array}$} & \multicolumn{2}{|c|}{$\begin{array}{l}\text { Adjusted for } \\
\text { baseline PCS }\end{array}$} & \multicolumn{2}{|c|}{$\begin{array}{l}\text { Not adjusted for } \\
\text { baseline MCS }\end{array}$} & \multicolumn{2}{|c|}{$\begin{array}{l}\text { Adjusted for } \\
\text { baseline PCS }\end{array}$} \\
\hline & OR & $95 \%$ CI & $p$ value & $\beta$ & $p$ value & $\beta$ & $p$ value & $\beta$ & $p$ value & $\beta$ & $p$ value \\
\hline Gender (female) & - & - & - & -0.03 & 0.73 & -0.05 & 0.55 & 0.09 & 0.49 & 0.00 & 0.99 \\
\hline Age & - & - & - & -0.13 & 0.15 & -0.12 & 0.10 & -0.10 & 0.40 & 0.16 & 0.19 \\
\hline \multicolumn{12}{|l|}{ Disease characteristics } \\
\hline \multicolumn{12}{|l|}{ Size } \\
\hline $0-5 \mathrm{~cm}$ & - & - & - & - & - & - & - & 0.26 & 0.04 & - & - \\
\hline$>5-10 \mathrm{~cm}$ & - & - & - & -0.12 & 0.28 & - & - & - & - & - & - \\
\hline$>10 \mathrm{~cm}$ & - & - & - & 0.15 & 0.19 & -0.01 & 0.89 & - & - & - & - \\
\hline \multicolumn{12}{|l|}{ Type } \\
\hline CVM & - & - & - & 0.06 & 0.49 & - & - & - & - & - & - \\
\hline $\mathrm{VM}$ & - & - & - & - & - & - & - & - & - & - & - \\
\hline LM & - & - & - & - & - & -0.11 & 0.13 & - & - & - & - \\
\hline LVM & - & - & - & - & - & - & - & - & - & - & - \\
\hline \multicolumn{12}{|l|}{ Depth/extent } \\
\hline Superficial (skin) & - & - & - & - & - & - & - & - & - & - & - \\
\hline Subcutaneous & 2.02 & $(0.64-6.31)$ & 0.23 & - & - & - & - & - & - & 0.13 & 0.26 \\
\hline Muscle & - & - & - & - & - & - & - & - & - & - & - \\
\hline Bone & 0.64 & $(0.16-2.58)$ & 0.53 & - & - & - & - & - & - & - & - \\
\hline \multicolumn{12}{|l|}{ Location } \\
\hline Head/neck & - & - & - & -0.30 & 0.17 & - & - & -0.10 & 0.57 & 0.19 & 0.45 \\
\hline Trunk & - & - & - & - & - & - & - & -0.14 & 0.28 & - & - \\
\hline Upper extremities & - & - & - & -0.20 & 0.25 & - & - & -0.26 & 0.08 & -0.05 & 0.80 \\
\hline Lower extremities & - & - & - & -0.44 & 0.03 & - & - & - & - & 0.29 & 0.19 \\
\hline \multicolumn{12}{|c|}{ Symptoms/complaints prior to treatment } \\
\hline Pain & - & - & - & -0.12 & 0.30 & - & - & - & - & -0.02 & 0.89 \\
\hline Itch & - & - & - & -0.15 & 0.12 & -0.09 & 0.23 & -0.05 & 0.67 & - & - \\
\hline Bleeding & - & - & - & - & - & - & - & - & - & - & - \\
\hline Recurrent infections & - & - & - & -0.14 & 0.16 & -0.08 & 0.36 & -0.04 & 0.75 & -0.11 & 0.39 \\
\hline Localized thrombosis & - & - & - & - & - & - & - & - & - & - & - \\
\hline $\begin{array}{l}\text { Impaired mobility of the affected } \\
\text { body part }\end{array}$ & - & - & - & -0.15 & 0.15 & -0.13 & 0.12 & - & - & 0.02 & 0.88 \\
\hline Location-specific symptoms* & - & - & - & - & - & - & - & - & - & - & - \\
\hline Fatigue & - & - & - & -0.35 & 0.001 & -0.16 & 0.05 & -0.12 & 0.39 & -0.09 & 0.46 \\
\hline Impaired physical condition & 1.91 & $(0.60-6.14)$ & 0.27 & -0.09 & 0.43 & - & - & -0.09 & 0.51 & - & - \\
\hline $\begin{array}{l}\text { Impaired in work or study-related } \\
\text { activities }\end{array}$ & - & - & - & -0.34 & 0.003 & -0.19 & $\mathbf{0 . 0 3}$ & -0.25 & 0.06 & -0.11 & 0.37 \\
\hline Impaired in social activities & - & - & - & -0.08 & 0.41 & - & - & - & - & - & - \\
\hline Dissatisfaction with appearance & 1.26 & $(0.44-3.63)$ & 0.67 & 0.22 & 0.04 & 0.07 & 0.36 & 0.15 & 0.30 & 0.05 & 0.72 \\
\hline $\begin{array}{l}\text { Psychological or emotional } \\
\text { complaints }\end{array}$ & - & - & - & - & - & - & - & -0.11 & 0.36 & & \\
\hline
\end{tabular}

Bold values indicate statistical significance $(p<0.05)$

*Location-specific symptoms are functional problems associated with the localization of the malformation near sensory organs, gastrointestinal or genito-urethral system, for example visual disturbance or difficulty swallowing. '-' $p>0.20$ in univariable regression analyses 


\section{Conclusion}

Bleomycin sclerotherapy generally leads to moderate patient-reported improvement in health and QoL in about half of treated patients, irrespective of the type, size and location of the lesion. Patient expectations should be managed accordingly.

\section{Compliance with Ethical Standards}

Conflict of interest On behalf of all authors, the corresponding author states that there is no conflict of interest.

Ethical Standard All procedures performed in studies involving human participants were in accordance with the ethical standards of the institutional and/or national research committee and with the 1964 Declaration of Helsinki and its later amendments or comparable ethical standards.

Informed Consent Formal consent is not required for this type of study, as individual patients indirectly consent to participate in the study when completing the questionnaire.

Open Access This article is distributed under the terms of the Creative Commons Attribution 4.0 International License (http:// creativecommons.org/licenses/by/4.0/), which permits unrestricted use, distribution, and reproduction in any medium, provided you give appropriate credit to the original author(s) and the source, provide a link to the Creative Commons license, and indicate if changes were made.

\section{References}

1. Wassef M, Blei F, Adams D, Alomari A, Baselga E, Berenstein A, et al. Vascular anomalies classification: recommendations from the international society for the study of vascular anomalies. Pediatrics. 2015;136(1):e203-14. https://doi.org/10.1542/peds. 2014-3673.

2. Dasgupta R, Fishman SJ. ISSVA classification. Semin Pediatr Surg. 2014;23(4):158-61. https://doi.org/10.1053/j.sempedsurg. 2014.06.016.

3. Breugem CC, Merkus MP, Smitt JH, Legemate DA, van der Horst CM. Quality of life in patients with vascular malformations of the lower extremity. Br J Plast Surg. 2004;57(8):754-63. https://doi.org/10.1016/j.bjps.2004.05.006.

4. Fahrni JO, Cho EY, Engelberger RP, Baumgartner I, von Kanel R. Quality of life in patients with congenital vascular malformations. Journal of Vascular Surgery Venous and Lymphatic Disorders. 2014;2(1):46-51. https://doi.org/10.1016/j.jvsv.2013. 09.001.

5. Zhang W, Chen G, Ren JG, Zhao YF. Bleomycin induces endothelial mesenchymal transition through activation of mTOR pathway: a possible mechanism contributing to the sclerotherapy of venous malformations. Br J Pharmacol. 2013;170(6):1210-20. https://doi.org/10.1111/bph.12355.

6. Narkio-Makela M, Makela T, Saarinen P, Salminen P, Julkunen I, Pitkaranta A. Treatment of lymphatic malformations of head and neck with OK-432 sclerotherapy induce systemic inflammatory response. Eur Arch Otorhinolaryngol. 2011;268(1):123-9. https:// doi.org/10.1007/s00405-010-1332-x.

7. Zhao JH, Zhao YF, Chen XM, Zheng X, Zhang WF. Histological investigation of veins and venous malformations after injection of sclerosing agents. Asian Journal of Oral and Maxillofacial Surgery. 2002;14(4):226-31.

8. Horbach SE, Lokhorst MM, Saeed P, de Gouyon Matignon de Pontouraude CM, Rothova A, van der Horst CM. Sclerotherapy for low-flow vascular malformations of the head and neck: A systematic review of sclerosing agents. JPRAS. 2015. https://doi. org/10.1016/j.bjps.2015.10.045.

9. Steiner F, FitzJohn T, Tan ST. Ethanol sclerotherapy for venous malformation. ANZ J Surg. 2014. https://doi.org/10.1111/ans. 12833.

10. Wiegand S, Eivazi B, Zimmermann AP, Sesterhenn AM, Werner JA. Sclerotherapy of lymphangiomas of the head and neck. Head Neck. 2011;33(11):1649-55. https://doi.org/10.1002/hed.21552.

11. Churchill P, Otal D, Pemberton J, Ali A, Flageole H, Walton JM. Sclerotherapy for lymphatic malformations in children: a scoping review. J Pediatr Surg. 2011;46(5):912-22. https://doi.org/10. 1016/j.jpedsurg.2011.02.027.

12. Horbach SE, Rigter IM, Smitt JH, Reekers JA, Spuls PI, van der Horst CM. Intralesional bleomycin injections for vascular malformations: a systematic review and meta-analysis. Plast Reconstr Surg. 2016;137(1):244-56. https://doi.org/10.1097/prs. 0000000000001924.

13. Blaise S, Charavin-Cocuzza M, Riom H, Brix M, Seinturier C, Diamand JM, et al. Treatment of low-flow vascular malformations by ultrasound-guided sclerotherapy with polidocanol foam: 24 cases and literature review. Eur J Vasc Endovasc Surg. 2011;41(3):412-7. https://doi.org/10.1016/j.ejvs.2010.10.009.

14. Gurgacz S, Zamora L, Scott NA. Percutaneous sclerotherapy for vascular malformations: a systematic review. Ann Vasc Surg. 2014;28(5):1335-49. https://doi.org/10.1016/j.avsg.2014.01.008.

15. Muir T, Kirsten M, Fourie P, Dippenaar N, Ionescu GO. Intralesional bleomycin injection (IBI) treatment for haemangiomas and congenital vascular malformations. Pediatr Surg Int. 2004;19(12):766-73. https://doi.org/10.1007/s00383-003-1058-6.

16. Froudarakis M, Hatzimichael E, Kyriazopoulou L, Lagos K, Pappas P, Tzakos AG, et al. Revisiting bleomycin from pathophysiology to safe clinical use. Critical Reviews in Oncology/ Hematology. 2013;87(1):90-100. https://doi.org/10.1016/j. critrevonc.2012.12.003.

17. Umezawa $\mathrm{H}$, Maeda K, Takeuchi T, Okami Y. New antibiotics, bleomycin A and B. J Antibiot. 1966;19(5):200-9.

18. Sikic BI. Biochemical and cellular determinants of bleomycin cytotoxicity. Cancer Surv. 1986;5(1):81-91.

19. Love Z, Hsu DP. Low-flow vascular malformations of the head and neck: clinicopathology and image guided therapy. J Neurointerv Surg. 2012;4(6):414-25. https://doi.org/10.1136/ neurintsurg-2011-010126.

20. Choi DJ, Alomari AI, Chaudry G, Orbach DB. Neurointerventional management of low-flow vascular malformations of the head and neck. Neuroimaging Clin N Am. 2009;19(2):199-218. https://doi.org/10.1016/j.nic.2009.01.003.

21. Spence J, Krings T, TerBrugge KG, Agid R. Percutaneous treatment of facial venous malformations: a matched comparison of alcohol and bleomycin sclerotherapy. Head Neck. 2011;33(1):125-30. https://doi.org/10.1002/hed.21410.

22. Ware JE Jr, Sherbourne CD. The MOS 36-item short-form health survey (SF-36). I. Conceptual framework and item selection. Med Care. 1992;30(6):473-83.

23. Coombes BK, Bisset L, Brooks P, Khan A, Vicenzino B. Effect of corticosteroid injection, physiotherapy, or both on clinical outcomes in patients with unilateral lateral epicondylalgia: a randomized controlled trial. JAMA. 2013;309(5):461-9. https:// doi.org/10.1001/jama.2013.129.

24. Hancock MJ, Maher CG, Latimer J, McLachlan AJ, Cooper CW, Day RO, et al. Assessment of diclofenac or spinal manipulative therapy, or both, in addition to recommended first-line treatment 
for acute low back pain: a randomised controlled trial. Lancet. 2007;370(9599):1638-43. https://doi.org/10.1016/s0140-6736(07) 61686-9.

25. Kamper SJ, Maher CG, Mackay G. Global rating of change scales: a review of strengths and weaknesses and considerations for design. J Man Manip Ther. 2009;17(3):163-70. https://doi. org/10.1179/jmt.2009.17.3.163.

26. Aaronson NK, Muller M, Cohen PD, Essink-Bot ML, Fekkes M, Sanderman R, et al. Translation, validation, and norming of the Dutch language version of the SF-36 Health Survey in community and chronic disease populations. J Clin Epidemiol. 1998;51(11):1055-68.
27. Blome C, Augustin M. Measuring change in quality of life: bias in prospective and retrospective evaluation. Value Health. 2015;18(1):110-5. https://doi.org/10.1016/j.jval.2014.10.007.

28. Oduber CE, Khemlani K, Sillevis Smitt JH, Hennekam RC, van der Horst CM. Baseline Quality of Life in patients with KlippelTrenaunay syndrome. JPRAS. 2010;63(4):603-9. https://doi.org/ 10.1016/j.bjps.2009.01.055.

29. Ono Y, Osuga K, Takura T, Nakamura M, Shibamoto K, Yamamoto A, et al. Cost-effectiveness analysis of percutaneous sclerotherapy for venous malformations. JVIR. 2016;27(6):831-7. https://doi.org/10.1016/j.jvir.2015.12.019. 